\title{
Chlorogenic acid alters the biological characteristics of basophil granulocytes by affecting the fluidity of the cell membrane and triggering pseudoallergic reactions
}

\author{
QIN LI, YIN ZHAO, XIAOLIANG ZHENG, QIUHONG CHEN and XINYUE ZHANG \\ Department of Pharmacology, Institute of Materia Medica, Zhejiang Academy of \\ Medical Sciences, Hangzhou, Zhejiang 310013, P.R. China
}

Received May 27, 2013; Accepted August 27, 2013

DOI: $10.3892 /$ ijmm.2013.1505

\begin{abstract}
It is not clear whether pseudoallergic reactions are caused by similar mechanisms as type I allergic reactions. 3-Caffeoylquinic acid (chlorogenic acid) is an active ingredient in traditional Chinese medicines used for antibacterial, anti-inflammatory and cholagogic purposes. It is assumed to be the reason for the high allergic reaction rates associated with certain traditional Chinese medicine injection solutions. The aim of the present study was to investigate the possible mechanisms through which chlorogenic acid triggers pseudoallergic reactions. The fluidity of the cell membrane was investigated using fluorescence recovery after photobleaching. Western blot analysis was used to measure the phosphorylation levels of the Spleen tyrosine kinase (Syk) protein and Fluo-3/AM fluorescent probes were used to investigate the influx of calcium ions. In addition, fluorescence microscopy and phalloidin were used to determine F-actin depolymerization levels. The secretion rate of $\beta$-hexosaminidase by RBL-2H3 cells clearly increased following treatment with chlorogenic acid and the levels of cytoskeletal disintegration were also markedly increased. Furthermore, we detected an increase in the intracellular calcium ion concentration along with distinct changes in Syk protein phosphorylation and cellular F-actin. These changes indicated that chlorogenic acid affected the restructuring of the cytoskeleton and played a role in cell degranulation. In conclusion, chlorogenic acid may lead to the aggregation of lipid rafts on the cell membrane surface by altering RBL-2H3 cell membrane fluidity, thus triggering
\end{abstract}

Correspondence to: Dr Xinyue Zhang, Department of Pharmacology, Institute of Materia Medica, Zhejiang Academy of Medical Sciences, No. 182 Tianmushan Road, Hangzhou, Zhejiang 310013, P.R. China

E-mail: zhangxinyueBM@163.com

Key words: chlorogenic acid, pseudoallergic reaction, RBL-2H3 cells
Syk-related signal transduction and inducing a truncated type I like allergic reaction.

\section{Introduction}

Chlorogenic acid is a phenolic acid and an ester of caffeic acid and quinic acid. It is a natural phenylpropanoid compound produced in the process of aerobic plant respiration through the shikimic acid pathway and occurs widely throughout the plant kingdom (1). Theoretically, based on the number of caffeic acids and the position of the esterification on the quinic acid, there are 10 possible structures for chlorogenic acids that contain either one or two caffeic acid groups (2). Of these, mono-caffeoylquinic acids are more widely distributed in plants with the most common being 3-caffeoylquinic acid, but other mono-caffeoylquinic acid compounds, in which the esterification occurs at either the 1, 3, or 4 position on the quinic acid, have also been extracted from plants. Dicaffeoylquinic acids exist widely in plants of the Asteraceae, Fabaceae, Apiaceae, Caprifoliaceae and Convolvulaceae families and some common ones are 1,5-dicaffeoylquinic acid, 3,5-dicaffeoylquinic acid, 4,5-dicaffeoylquinic acid and 3,4-dicaffeoylquinic acid, whereas caffeoylquinic acids containing three or more caffeic acid groups only exist in a few types of plants $(2,3)$. As chlorogenic acid is an active ingredient with antibacterial, anti-inflammatory and cholagogic properties, the majority of the traditional Chinese medicine injection solutions for reducing fevers and controlling infections contain chlorogenic acid. An analysis of Chinese scientific articles on traditional Chinese medicine showed that traditional Chinese medicine injection solutions, such as Shuanghuanglian and Qingkailing, which contain relatively high amounts of chlorogenic acid, clearly induce a higher rate of allergic reactions when administered intravenously $(4,5)$. However, the majority of the cases experienced an allergic reaction upon first exposure to the drug without sensitization processes (6). Furthermore, the reactions were drug dose- and concentration-dependent (7). Therefore, we assume that at least a large proportion of the clinically reported allergic reactions were actually pseudoallergic reactions.

Pseudoallergic reactions refer to clinical reactions that do not involve the immune system, but rather are mediated 
chemically or pharmacologically and show symptoms similar to an allergic reaction upon first exposure to a drug. Drugs directly stimulate mast cells and basophil granulocytes to secrete large amounts of allergy mediators, such as histamine, thus creating symptoms similar to an allergic reaction $(6,8)$. The concept of pseudoallergic reactions was first introduced in the field of anesthesia. $\mathrm{C} 48 / 80$ is a mixture formed by the synthesis of 3-6 units of N-methyl-4-methoxyphenethylamine and formaldehyde and can effectively induce mast cell degranulation, as well as effectively induce histamine secretion (9). It conjugates with the $\mathrm{Fc}$ region of immunoglobulin $(\mathrm{Ig}) \mathrm{E}$ receptors on the surface of mast cells, triggering a truncated type I allergic reaction. In addition, it can increase the calcium flow inside the cell by inducing the release of calcium from the endoplasmic reticulum. This has been shown to be a possible energy source for the release of granules from mast cells, indicating that $\mathrm{C} 48 / 80$ can induce pseudoallergic reactions in cells $(10,11)$. Injection solutions used clinically in Chinese medicine typically have complex ingredients, with many additives from the production process. Therefore large amounts of drug can enter the bloodstream rapidly (particularly when administered incorrectly), where they come into direct contact with basophil granulocytes, which mainly reside in the blood. They are likely to cause the latter to undergo non-immune degranulation; in other words, a pseudoallergic reaction.

The Fc receptors (FcRs) that bind $\mathrm{IgG}$ and $\mathrm{IgE}$ are two of the most common and most functionally active receptors of the immune system. IgG and IgE are recognized by FceR and Spleen tyrosine kinase (Syk) is an important signaling molecule in $F c \gamma R$ and FceR signal transduction. In type I allergic reactions, after a multivalent antigen binds to $\operatorname{IgE}$ and leads to the coupling of two or more FceRI, mast cells become activated. The coupling of FceRI leads to the activation of Lyn and Syk, while activated Lyn phosporylates and activates Btk and Emt. Btk causes an efflux of calcium ions, while Emt activates protein kinase $\mathrm{C}$ (PKC). The activation of PKC and the efflux of calcium ions are both necessary steps for degranulation. Activated FceRI also leads to the release of granules into the cytoplasm and active substances in the granules, such as histamine, interleukin, cytokines, as well as TNF- $\alpha$ can lead to various reactions, which are associated with inflammation and allergies. Activated Syk can further activate other substrates, including linker for activation of $\mathrm{T}$ cells (LAT) and white blood cell proteins that contain the $\mathrm{SH} 2$ domain, such as SH2 domain-containing leukocyte protein of $76 \mathrm{kDa}$ (SLP76), Vav, Grb2-associated binder 2 (Gab2) and phospholipase C (PLC) $\gamma$ (12), which can in turn activate the AKT and $\mathrm{MEK} / \mathrm{ERK}$ signaling pathways. In pseudoallergic reaction experiments, whenever Syk protein activation is discovered, a large influx of calcium ions can be observed, suggesting that pseudoallergic reactions may be a type of truncated type I allergic reaction. When a cell degranulates, the dense basophilic vesicles in the cytoplasm move towards the cell membrane under the guidance of the cytoskeleton $(13,14)$.

Previous studies have indicated that the degranulation of mast cells or basophil granulocytes takes place through two processes (15): i) The calcium ion-dependent binding of granules at the cell membrane. If the calcium ion concentration in the cytoplasm is too high, it causes phosphate ions to precipitate, leading to a reduction in adenosine triphosphate (ATP) levels, which in turn causes a change in the structure of the cell membrane (16). In addition, calcium ion concentrations can affect the depolymerization process of F-actin. Through research on the p21-activated kinase (PAK) family members PI3K and RhoGTPase, it has been demonstrated (17) that it is possible to affect the cytoskeleton and degranulation processes by regulating calcium levels. ii) Calcium ion-independent granule migration. Nishida et al (12) suggested that in the restructuring of the cytoskeleton activated by FceRI, there is a calcium ion-independent microtubule (MT) restructuring process. They hypothesized that Fyn activation can lead to the sequestering of Gab2 protein, which activates RhoA, leading to MT restructuring, which then causes granules in the cell to migrate.

Based on the above data, we hypothesized that chlorogenic acid can induce pseudoallergenic effects in basophil granulocytes by binding with IgE, which leads to the coupling of two or more FceRI, altering the fluidity of the cell membrane with activated Syk and its downstream signaling.

\section{Materials and methods}

Cell culture. RBL-2H3 cells are rat basophil leukemia cells, purchased from the Cell Bank of Chinese Academy of Sciences, Shanghai, China. They were cultured in DMEM with $10 \% \mathrm{FBS}$ at $37^{\circ} \mathrm{C}$ and $5 \% \mathrm{CO}_{2}$. Cells in the logarithmic growth period were used for the experiments. Pre-experiments testing the effect of $\mathrm{C} 48 / 80$ as the positive control on basophil granulocytes showed that the optimal density and time period for inducing degranulation were $2 \times 10^{5}$ cells $/ \mathrm{ml}$ and $60 \mathrm{~min}$.

Measurement of hexosaminidase secretion rates. The amount of histamine secretion is the most direct and reliable indicator of degranulation in RBL-2H3 cells $(18,19)$. However, as histamine has a short half-life, low molecular weight and poor immunogenicity, clinically it is more common to use $\beta$-hexosaminidase measurements to evaluate pseudoallergic reactions, as in vitro, $\beta$-hexosaminidase secretion by RBL-2H3 cells is concomitantly increased by degranulation. RBL-2H3 cells were plated in 24-wells cell and incubated overnight at a density of $2 \times 10^{5}$ cells/well. The following day, the cells were washed three times with incubation buffer and $100 \mu \mathrm{l}$ of incubation buffer were added to each well followed by incubation for $10 \mathrm{~min}$ at $37^{\circ} \mathrm{C}$. Subsequently, $100 \mu \mathrm{l}$ of various 3-caffeoylquinic acid concentrations or an equal amount of negative control (buffer) were added and the cells were incubated at $37^{\circ} \mathrm{C}$ for $60 \mathrm{~min}$. Following incubation, the cells were placed in an ice bath for $10 \mathrm{~min}$ to terminate the reaction. Subsequently, $50 \mu 1$ supernatant from each well were transferred to a 96 -well plate and $50 \mu \mathrm{l}$ of substrate were added ( $1 \mathrm{mM}$ p-nitrophenyl-N-acety- $\beta$-D-glucosaminide, citrate/sodium citrate buffer, $\mathrm{pH}$ 4.5). The samples were incubated at $37^{\circ} \mathrm{C}$ for $60 \mathrm{~min}$ and then $150 \mu \mathrm{l}$ of stop solution (0.1 $\left.\mathrm{M} \mathrm{Na}_{2} \mathrm{CO}_{3} / \mathrm{NaHCO}_{3}, \mathrm{pH} 10.0\right)$ were added to terminate the reaction. The light absorbance at $405 \mathrm{~nm}$ was measured in each well as a quantitative analysis of $\beta$-hexosaminidase secretion. In the 24-well plates, the remaining supernatant was removed and $200 \mu \mathrm{l}$ of Triton X-100 (0.5\%) were added to lyse the cells. The cell lysate was centrifuged at 3,000 rpm for $1 \mathrm{~min}$ and $50 \mu \mathrm{l}$ supernatant (four times) were transferred 
to a 96-well plate in order to measure the intracellular $\beta$-hexosaminidase concentration in the cell lysates. The following formula was used to calculate the $\beta$-hexosaminidase secretion rate: $\beta$-hexosaminidase secretion rate $(\%)=[$ supernatant light absorbance/(supernatant light absorbance + lysate light absorbance)] x100\%.

Electron microscopy. RBL-2H3 cells $\left(1 \times 10^{7}\right)$ from the negative control group and from the group treated with various concentrations of 3-caffeoylquinic acid $1 \mathrm{~h}$ were collected, washed thoroughly with pre-chilled PBS and centrifuged at 1,500 rpm for $10 \mathrm{~min}$ at $4^{\circ} \mathrm{C}$. Pre-chilled $2.5 \%$ glutaraldehyde was added to the centrifuge tubes where a cell mass had formed after centrifugation and the mixture was incubated overnight at $4^{\circ} \mathrm{C}$. Finally, the samples were fixed with $1 \%$ osmium tetroxide at $4^{\circ} \mathrm{C}$, then dehydrated and permeated according to normal electron microscopy sample preparation procedures. The samples were then embedded in Epon 812, cut into ultrathin slices, stained according to normal procedures and photographed under an H-600A Transmission Electron Microscope (Hitachi High-Technologies Corp., Tokyo, Japan).

Measurement of Syk protein phosphorylation levels. Cells were plated in a petri dish and on the following day, the cells were treated with either the drug or negative control (no drug) for $1 \mathrm{~h}$ in incubation buffer. Subsequently, the cells were washed twice with pre-chilled PBS and an appropriate amount of IP cell lysis buffer (containing proteinase inhibitor; Amresco, Solon, OH, USA) was added and after the cells were lysed on ice for $30 \mathrm{~min}$ they were centrifuged at $15,000 \mathrm{x} \mathrm{g}$ for $15 \mathrm{~min}$ at $4^{\circ} \mathrm{C}$. An aliquot of the supernatant was used to measure the protein content using a BCA Assay (Amresco). A small amount of lysate was saved for western blot analysis and to the remaining lysate, $1 \mu \mathrm{g}$ of $4 \mathrm{G} 10$ antibody (Santa Cruz Biotechnology, Inc., Santa Cruz, CA, USA) and 10-50 $\mu 1$ of protein G-beads were added followed by overnight incubation at $4^{\circ} \mathrm{C}$ with gentle agitation. After the immunoprecipitation reaction, the magnetic beads were stabilized with a magnet while the supernatant was carefully removed. Protein G-beads were washed three to four times with $500 \mu \mathrm{l}$ lysis buffer followed by the addition of $10 \mu 1$ 5X SDS loading buffer and boiling for $5 \mathrm{~min}$. The cell lysis supernatants and immunoprecipitation samples were run through SDS-PAGE for $100 \mathrm{~min}$ at $90 \mathrm{~V}$ for separation and the proteins were then transferred onto a PVDF membrane for western blot analysis. TBST with 5\% non-fat milk was used for blocking at room temperature for $1 \mathrm{~h}$. After removing the blocking buffer, the primary antibody, anti-Syk, was added (1:500 dilution; Santa Cruz Biotechnology, Inc.) and the membranes were incubated at room temperature for $2 \mathrm{~h}$ with gentle agitation. The primary antibody was then removed and the membranes were washed with TBST for 3x10 min. Finally, secondary antibody coupled with horseradish peroxidase was added (1:6,000 dilution) at room temperature for $1 \mathrm{~h}$ with gentle agitation. Then the secondary antibody was removed and the membrane was washed with TBST for 3x10 min. Extra liquid was removed with filter paper and ECL chemiluminescence reagent was added (ECL reagents and PMSF proteinase inhibitors were both purchased from Biyuntian Biotech, Jiangsu, China). An Alpha Innotech imaging system was used for detec- tion $(20,21)$. For further calculations the following formula was used:

$\begin{gathered}\% \text { Syk } \\ \text { phosphorylation }\end{gathered}=\left(\begin{array}{c}\begin{array}{c}\text { phospho }- \text { Syk } \\ \text { band density }\end{array} \\ \begin{array}{c}\text { IP total } \\ \text { protein content }\end{array}\end{array}\right) \div\left(\frac{\begin{array}{c}\text { Syk total protein } \\ \text { band density }\end{array}}{\begin{array}{c}\text { western blot total } \\ \text { protein content }\end{array}}\right) \times 100 \%$

Detection of calcium ion influx. A total of $1 \times 10^{5}$ cells $/ \mathrm{ml}$ were plated in a $35-\mathrm{mm}$ glass-bottom petri dish the previous day and grown overnight. The following day, the extra DMEM medium was removed, the cells were washed twice with D-Hank's medium and $500 \mu \mathrm{l}$ D-Hank's medium were added. After $10 \mathrm{~min}$ of incubation at $37^{\circ} \mathrm{C}$ in a $\mathrm{CO}_{2}$ incubator, $500 \mu \mathrm{l}$ of $10 \mu \mathrm{M}$ Fluo-3 AM working solution were added (final concentration $5 \mu \mathrm{M}$ ) and th esamples were incubated for $30 \mathrm{~min}$ in an incubator. Following incubation, D-Hank's medium was used to wash away extra probes. Fluo-3 AM is a fluorescent dye that can penetrate the cell membrane and its fluorescence is very weak without intensifying higher calcium ion concentrations. After Fluo-3 AM enters the cell and is cleaved by esterases inside the cell, it becomes Fluo-3, which is trapped inside the cell and binds to calcium ions. Fluo-3 is not fluorescent when not bound to calcium ions, but when bound to calcium ions its fluorescence $(526 \mathrm{~nm})$ increases by a factor of at least 40 . In the actual experiment, the recommended excitation wavelength was approximately $488 \mathrm{~nm}$ and emission wavelength was 525-530 nm. Samples were photographed under a confocal microscope to use as a background and the changes in intracellular calcium ion concentration were observed as the appropriate drug was slowly added.

Quantitative detection of F-actin. Cells were treated with the appropriate drug or an equal amount of negative control (incubation buffer) for $1 \mathrm{~h}$, after which the drug or buffer was removed and the cells were washed three times with PBS. Cells were fixed with $4 \%$ paraformaldehyde at room temperature for $15 \mathrm{~min}$, washed with PBS for $30 \mathrm{sec}$, permeabilized with $0.5 \%$ Triton X-100 for $10 \mathrm{~min}$ and washed again with PBS for $30 \mathrm{sec}$. Subsequently, $200 \mu \mathrm{l}$ of $100 \mathrm{nM}$ rhodamine-phalloidin (purchased from Cytoskeleton, Inc., Denver, CO, USA) were added, the samples were incubated in the dark at room temperature for $30 \mathrm{~min}$, washed three times with PBS and photographed under a confocal laser microscope. Alternatively, $300 \mu \mathrm{l}$ of methanol were added and the samples were incubated in the dark for $2 \mathrm{~h}$. The supernatant was transferred to a black plate with a transparent bottom and fluorescence was detected at 535/590 nm.

NBD-C6-HPC cell membrane fluidity test. Cells were plated the previous day. To each well $2 \mu \mathrm{M}$ NBD-C6-HPC dye (NBD-C6-HPC fluorescent dye was purchased from Invitrogen, Carlsbad, CA, USA) was added and the samples were incubated at room temperature in the dark for $30 \mathrm{~min}$, washed three times with PBS, treated with the appropriate drug or an equal amount of negative control (incubation buffer) for $1 \mathrm{~h}$ and washed again three times with PBS. Under a confocal laser, a circular area on the cell membrane of a fixed size was selected and changes in membrane fluidity were observed 


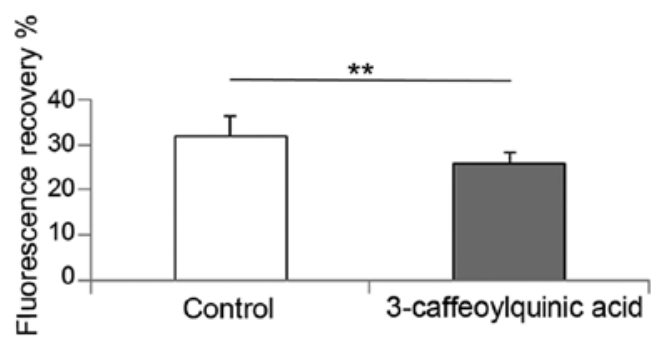

Figure 1. Membrane fluidity of RBL-2H3 cells. Membrane fluidity was detected by fluorescence recovery after photobleaching (FRAP) with NBD-C6-HPC fluorescent dye. ${ }^{* *} \mathrm{P}<0.01$.

Table I. Secretion of $\beta$-hexosaminidase by RBL-2H3 cells following treatment with various $\mathrm{C} 48 / 80$ concentrations with different incubation times (\%).

\begin{tabular}{lccr}
\hline Concentration/time & $30 \mathrm{~min}$ & $60 \mathrm{~min}$ & $120 \mathrm{~min}$ \\
\hline $4 \times 10^{4}$ & 0.63 & 21.51 & 9.84 \\
$2 \times 10^{5}$ & 1.21 & 46.53 & 11.25 \\
$1 \times 10^{6}$ & 6.53 & 52.72 & 25.42 \\
\hline
\end{tabular}

using photo bleaching. The formula used for calculating the fluorescence recovery was as follows:

$$
\text { Fluorescence recovery }=\frac{\mathrm{F}_{\mathrm{R}}-\mathrm{F}_{0}}{\mathrm{~F}_{1}-\mathrm{F}_{0}} \%
$$

where $F_{R}$ is the maximum fluorescence intensity after recovery, $\mathrm{F}_{0}$ is the fluorescence intensity after photo bleaching and $F_{1}$ is the fluorescence intensity before photo bleaching (22).

Statistical analyses. Each of the in vitro experiments presented in this study were repeated multiple $(\geq 3)$ times. A one-way analysis of variance (ANOVA) was used for the comparison of multiple experimental groups. When ANOVA yielded significance, pairwise comparisons using a t-test with the Bonferroni adjustment were conducted between two groups. The results were considered statistically significant if a two-tailed P-value was $<0.05$.

\section{Results}

3-Caffeoylquinic acid enhances $\beta$-hexosaminidase secretion rates. Treating $\mathrm{RBL}-2 \mathrm{H} 3$ basophil granulocytes with $\mathrm{C} 48 / 80$ as the positive control showed that the RBL-2H3 cells secreted $\beta$-hexosaminidase in a dose- and time-dependent manner (Table I). After $60 \mathrm{~min}$ of $\mathrm{C} 48 / 80$ incubation, the relative $\beta$-hexosaminidase secretion rate by $\mathrm{RBL}-2 \mathrm{H} 3$ cells reached a maximum, which dropped to lower levels after an additional hour in all groups. Treating RBL-2H3 cells with C48/80 can be used as a positive control for pseudoallergic reactions. We used chlorogenic acid and its analogues (3-caffeoylquinic acid, 4-caffeoylquinic acid, 3,4-dicaffeoylquinic acid and 1,5-dicaffeoylquinic acid) to test whether a similar reaction occurs with caffeoylquinic acids. Both mono-caffeoylquinic acids and dicaffeoylquinic acids induced RBL-2H3 cells to secrete $\beta$-hexosaminidase in a concentration-dependent manner after 60 min of incubation. The pseudoallergic reactions induced by dicaffeoylquinic acids were relatively weaker compared with those induced by mono-caffeoylquinic acids (Table II). These results revealed that 3 -caffeoylquinic acid induces pseudoallergic reactions in RBL-2H3 cells.

3-Caffeoylquinic acid alters the fluidity of the cell membrane. Since RBL-2H3 is a rat basophilic leukemia cell line, the cells have high affinity $\operatorname{IgE}$ receptors on their surface and they can undergo degranulation following activation. Thus, in this study, we performed a NBD-C6-HPC assay experiment to monitor the cell membrane fluidity of the RBL-2H3 cells. 3-Caffeoylquinic acid $(1.0 \mathrm{mmol} / \mathrm{l})$ was added to the RBL-2H3 cells for $60 \mathrm{~min}$ and by comparing the fluorescence intensity before photo bleaching, after photo bleaching and after recovery, we found that cells in the 3-caffeoylquinic acidtreated group showed significantly lower fluorescence recovery compared with the cells in the negative control group (Fig. 1). This indicates a change in the fluidity of the cell membrane molecules. We also used electron microscopy to observe the ultrastructures of the cell membranes (Fig. 2). The results revealed that in the negative control group, the RBL-2H3 cells had a clear nucleolus, the cell membranes had more micro-

Table II. Effect of analogues of 3-caffeoylquinic acid assessed by the secretion of $\beta$-hexosaminidase by RBL-2H3 cells.

$\beta$-hexosaminidase release at different concentrations $(\%)$

\begin{tabular}{llll}
\cline { 3 - 3 } Concentration & Control & $0.2 \mathrm{mmol} / \mathrm{l}$ & $1 \mathrm{mmol} / \mathrm{l}$
\end{tabular}

\section{$1.70 \pm 0.42$}

3-Caffeoylquinic acid

4-Caffeoylquinic acid

3,4-Dicaffeoylquinic acid

1,5-Dicaffeoylquinic acid

$2.26 \pm 0.46$
$3.64 \pm 0.24^{\mathrm{a}, \mathrm{b}}$
$1.35 \pm 0.52^{\mathrm{b}}$
$3.85 \pm 0.20^{\mathrm{a}, \mathrm{b}}$

$23.61 \pm 5.42^{\mathrm{a}}$

$25.83 \pm 6.33^{\mathrm{a}, \mathrm{b}}$

$6.16 \pm 1.87^{\mathrm{a}, \mathrm{b}}$

$13.49 \pm 2.92^{\mathrm{a}, \mathrm{b}}$
$75.04 \pm 1.54^{\mathrm{a}}$

$82.16 \pm 1.23^{\mathrm{a}, \mathrm{b}}$

$14.76 \pm 2.88^{\mathrm{a}, \mathrm{b}}$

$18.03 \pm 2.71^{\mathrm{a}, \mathrm{b}}$

${ }^{\mathrm{a}} \mathrm{P}<0.01,3$-caffeoylqunic acid, 4-caffeoylqunic acid, 3,4-dicaffeoylqunic acid and 1,5-dicaffeoylqunic acid vs. Control, t-test. ${ }^{\mathrm{b}} \mathrm{P}<0.01,4$-caffeoylqunic acid, 3.4-dicaffeoylqunic acid and 1,5-dicaffeoylqunic acid vs. 3-caffeoylqunic acid at the same concentration, t-test. Data represent the means \pm SD, $\mathrm{n}=5$. 


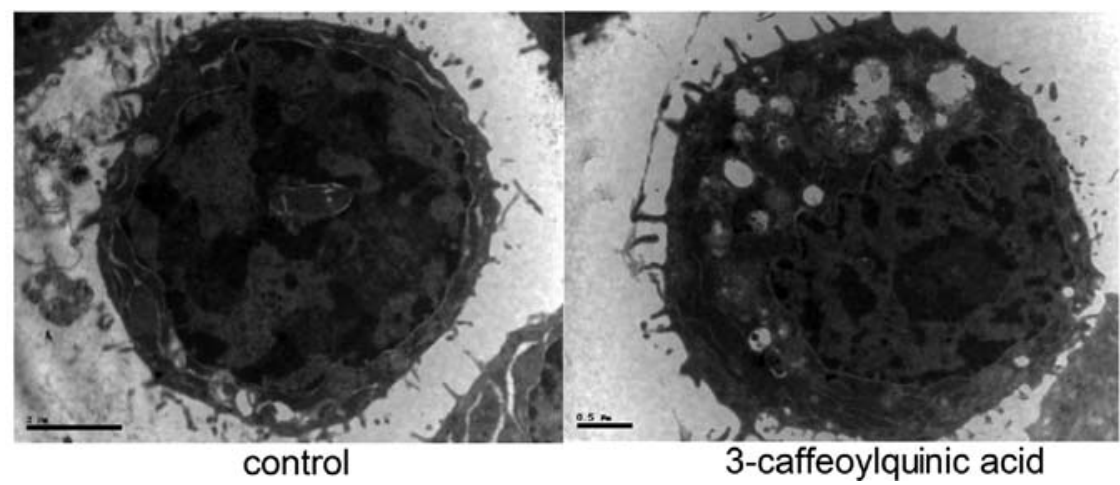

Figure 2. Effect of analogues of 3-caffeoylquinic acid on ultrastructure of RBL-2H3 cells. We used electron microscopy to observe the ultrastructures of the cell membranes. In the negative control group, the RBL-2H3 cells had a clear nucleolus, the cell membranes had more microvilli and in the cytoplasm there were grain-like structures of varying sizes. By contrast, in the cells treated with 3-caffeoylquinic acid, there was a marked increase in the number of empty vesicles in the cytoplasm, the chromatin in the nucleus was more agglomerated and most significantly, the number of granules in the cells was reduced, the cytoplasm was thinner, and the number of vesicles had increased. In addition, a large number of empty bubble-like structures appeared and the granule-containing vesicles migrated towards the cell membrane, fused with it for exocytosis; these features are typical of degranulation

A

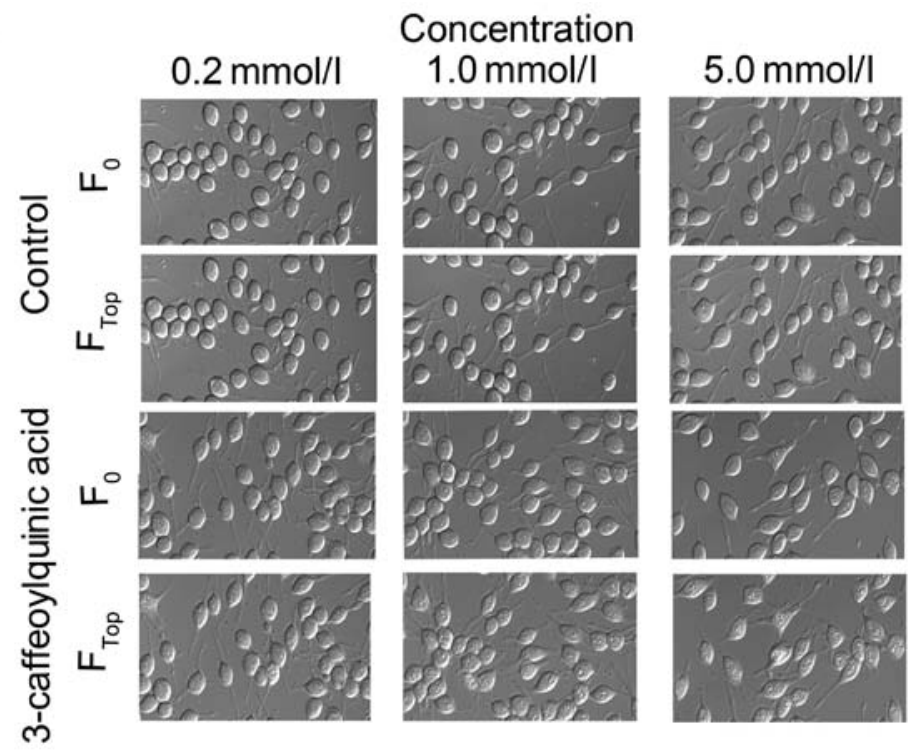

B

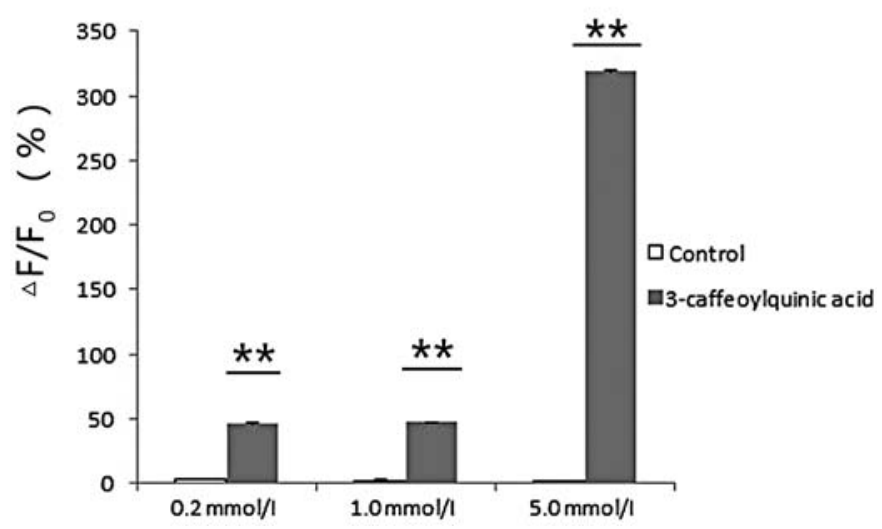

Figure 3. (A) The calcium influx detection by Fluo-3 AM fluorescent dye. $\mathrm{F}_{\mathrm{Top}}$, maximum fluorescence intensity; $\mathrm{F}_{0}$, the initial fluorescence intensity. (B) Calcium ion influx measured by $\triangle \mathrm{F} / \mathrm{F}_{0}(\%){ }^{* * *} \mathrm{P}<0.01$.

villi and in the cytoplasm there were grain-like structures of varying sizes, while the cells contained dense granules. By contrast, in the cells treated with 3-caffeoylquinic acid, there was a marked increase in the number of empty vesicles in the cytoplasm, the chromatin in the nucleus was more agglomerated and most significantly, the number of granules in the cells 
A

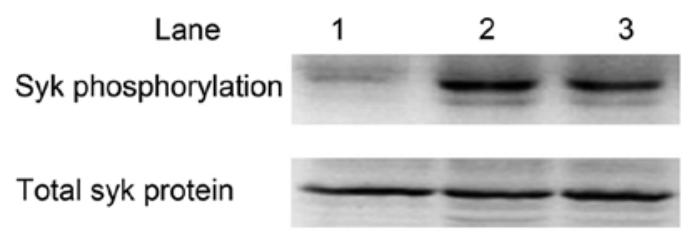

B

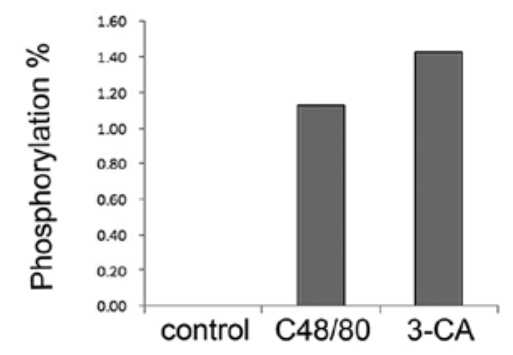

Figure 4. (A) Western blot analysis of changes in spleen tyrosine kinase (Syk) protein phosphorylation following treatment with C48/80 (lane 2) or 3-caffeoylquinic acid (lane 3); lane 1, control. (B) Quantitative analysis of the phosphorylation of Syk protein.

were reduced, the cytoplasm was thinner, and the number of vesicles had increased. In addition, a large number of empty bubble-like structures appeared and the granule-containing vesicles migrated towards the cell membrane, fused with it for exocytosis; these features are typical of degranulation (Fig. 2).

3-Caffeoylquinic acid alters cell membrane fluidity and increases calcium ion influx. Since a change in the fluidity of the cell membrane can affect the concentrations of calcium ions inside and outside the membrane, we measured the concentration of calcium ions inside the RBL-2H3 cells treated with 3-caffeoylquinic acid. We found that after treatment with $5.0 \mathrm{mmol} / 13$-caffeoylquinic acid, the calcium ion level in the RBL-2H3 cells increased and binding with Fluo-3 caused a $300 \%$ higher fluorescence signal, indicating that a high 3-caffeoylquinic acid concentration can induce changes in the calcium ion concentration; furthermore, the rate of calcium ion influx increased in a basically linear fashion along with the drug treatment time (Fig. 3).

3-Caffeoylquinic acid induces the phosphorylation of Syk on the cell membrane. Syk is an important kinase for signal transduction pathways of B cell activation and an important signaling molecule for $F c \gamma R$ and FceR signal transduction. RBL-2H3 is a rat basophilic leukemia cell line with high affinity IgE receptors on the surface of the cells and the FcR of $\operatorname{IgE}$ can be recognized by $\mathrm{Fc} \gamma \mathrm{R}$ and FceR. Thus, when a multivalent antigen (such as 3-caffeoylquinic acid) binds with IgE and causes two or more FceRI to couple, it can activate mast cells, leading to Syk phosphorylation, which activates PKC. We measured phospho-Syk and total Syk protein $60 \mathrm{~min}$ after the addition of $1 \mathrm{mmol} / 1$ of 3-caffeoylquinic acid to the cells and found that 3-caffeoylquinic acid induced Syk phosphorylation in the RBL-2H3 cells (Fig. 4).

Effect of 3-caffeoylquinic acid on F-actin. The polymers of the cytoskeleton control the morphology and kinetics of eukaryotic cells and consist of three major forms: actin filaments (AFs), MTs and intermediate filaments (IFs). These three components are organized into a network to resist changes in cell shape, but in response to an external force, they can reorganize themselves, thus playing an important role in maintaining cell integrity. Our quantitative F-actin measurements in the RBL-2H3 cells treated with 3-caffeoylquinic acid revealed that in the 3-caffeoylquinic acid-treated group, compared with the negative control group, significantly more actin depolymerization occurred (Fig. 5), indicating that 3-caffeoylquinic acid induces the reorganization of the cytoskeleton.

\section{Discussion}

Caffeoylquinic acid compounds (chlorogenic acids) are a type of ingredient that occurs widely in plants and used in traditional Chinese medicine for antibacterial, antitoxic, anti-inflammatory and cholagogic purposes. It is used therapeutically, but when administered intravenously, it can lead to a significantly higher rate of allergy incidences (23). In the present study, we investigated whether chlorogenic acid triggers pseudoallergic reactions. After analyzing the fluidity of the cell membrane, calcium ion influx, Syk protein phosphorylation and changes in F-actin content, we came to the conclusion that chlorogenic acid affects RBL-2H3 cells by reducing the fluidity of the cell membrane (Fig. 2). We proved that there was a change in the calcium ion concentration inside and outside the cells and that Syk was phosphorylated. Thus, we suggest a mechanism by which chlorogenic acid triggers a pseudoallergic reaction in RBL-2H3 cells as shown in Fig. 6. Lateral drifting of lipid rafts on the cell membrane allowed activated receptors to join with signal transduction molecules, leading to a reduction in the fluidity of the cell membrane. First, the Fc region of IgE on RBL-2H3 cell membranes is recognized by FceR (24). This binding leads to the coupling of two or more FceRI, thereby triggering Syk phosphorylation, which in turn activates its substrates, including LAT and white blood cell proteins that contain SH2 domains, such as SLP76, Vav, Gab2 and PLC- $\gamma 20$ (12), each activating more other signaling pathways. In addition, PTK, which is a member of the Lyn and Syk family, becomes activated and in turn activates PKC, which leads to the increased influx of extracellular calcium and as a final result, degranulation is triggered.

The cytoskeleton is mainly composed of MTs, microfilaments and IFs. It not only plays important roles in maintaining cell morphology, resisting external forces and keeping the internal structures of the cells organized, but also participates in several important biological activities (25). By studying the PAK family members, PI3K and RhoGTPase, Allen et al (17) demonstrated that by regulating calcium, one can affect the cytoskeleton and the degranulation process. This study also showed that calcium ion concentration can affect 
A
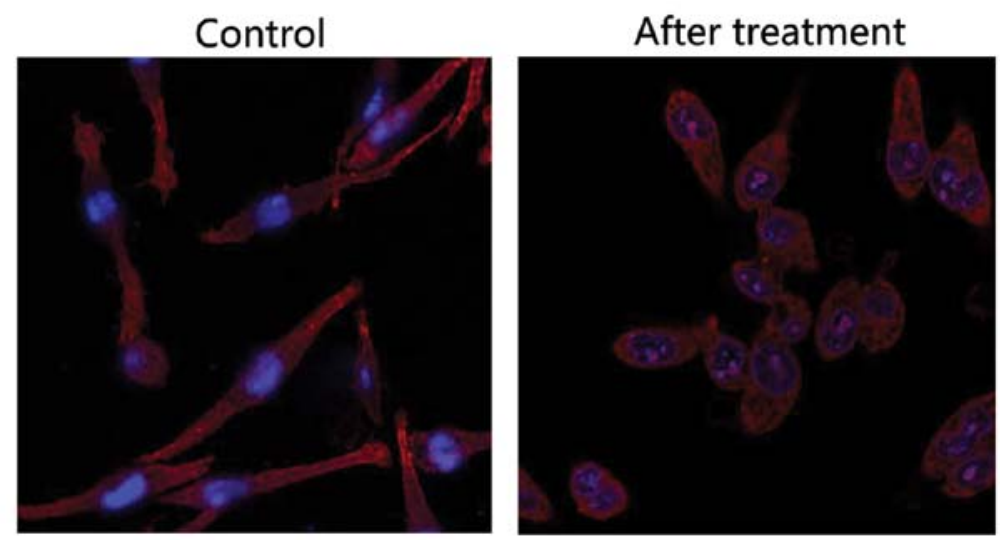

B

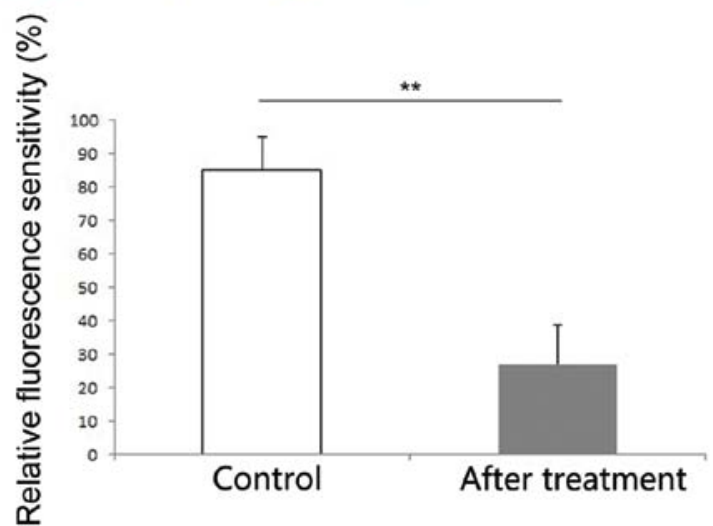

Figure 5. Changes in F-actin depolymerization in RBL-2H3 cells treated with $1 \mathrm{mmol} / 13$-caffeoylqunic acid (n=3). (A) Fluorescence microscopy images of RBL-2H3 cells either untreated (control) or after treatment with $1 \mathrm{mmol} / 1$ caffeoylquinic acid (blue, nuclei; red, F-actin). (B) Quantitative analysis of F-actin. *" $\mathrm{P}<0.01$.

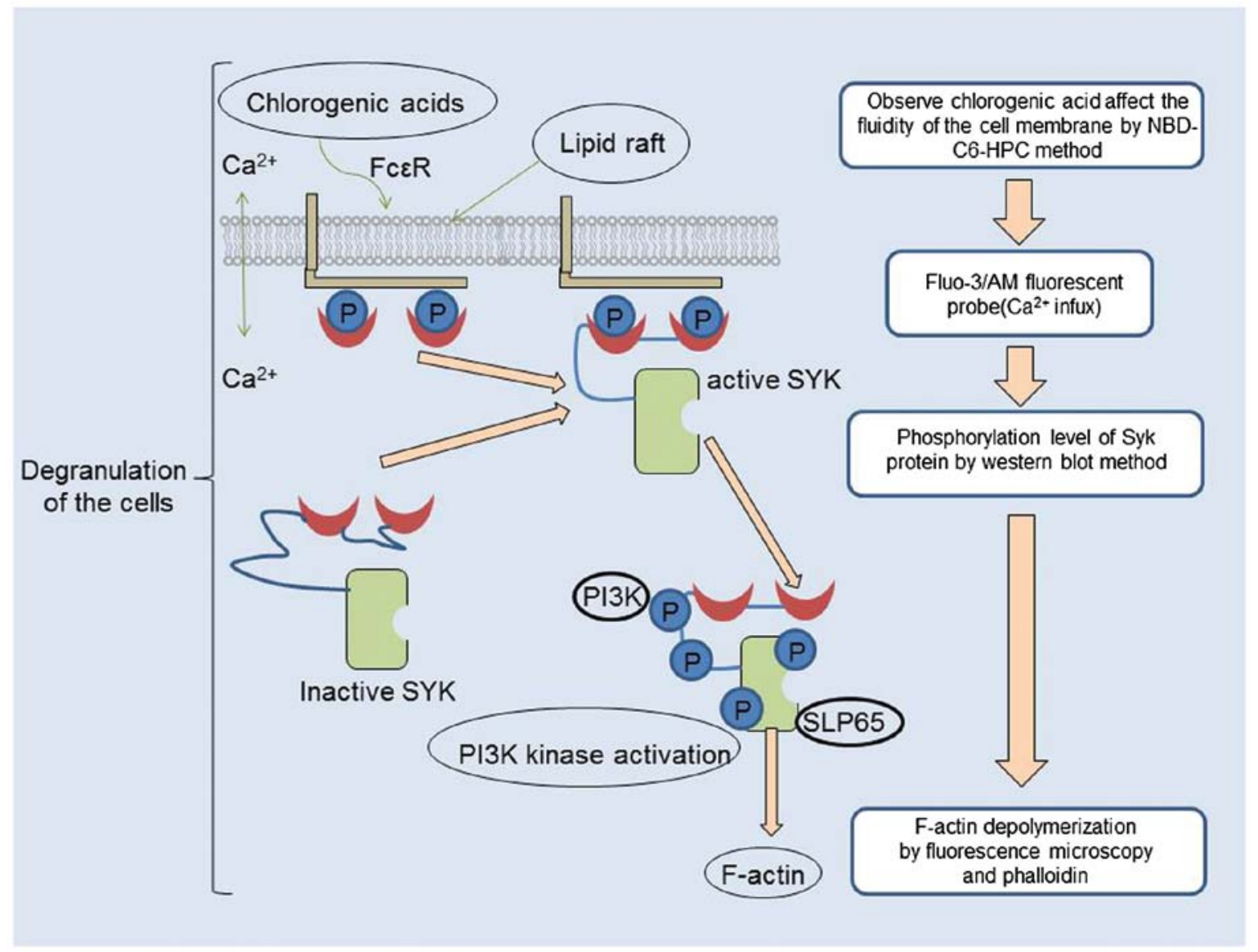

Figure 6. Schematic diagram of the mechanisms of pseudoallergic reactions induced by chlorogenic acids. 
the depolymerization process of F-actin and during RBL-2H3 degranulation, the dense basophil granules in the cytoplasm moved towards the cell membrane under the guidance of the cytoskeleton.

In conclusion, 3-caffeoylquinic acid induced lipid raft aggregation on the cell membrane of RBL-2H3 cells, degranulation, as well as Syk phosphorylation and calcium ion influx, thereby inducing F-actin depolymerization. 3-Caffeoylquinic acid can trigger a pseudoallergic reaction in a manner similar to $\mathrm{C} 48 / 80$.

\section{Acknowledgements}

We specially thank Gaoli Zheng for the experimental design and guidance. The present manuscript was supported by grants from the Natural Science Foundation of Zhejiang Province (Y2090514).

\section{References}

1. Lin M, Gong W, Wang Y, Sun L and Fan X: Structure-activity differences of chlorogenic acid and its isomers on sensitization via intravenous exposure. Int J Toxicol 31: 602-610, 2012.

2. Ho YC, Yu HT and Su NW: Re-examination of chromogenic quantitative assays for determining flavonoid content. J Agric Food Chem 60: 2674-2681, 2012.

3. Clifford MN, Johnston KL, Knight S and Kuhnert N: Hierarchical scheme for LC-MSn identification of chlorogenic acids. J Agric Food Chem 51: 2900-2911, 2003.

4. Peng B, He R, Xu Q, Gao J, Lu Y and Li J: Effect of chlorogenic acid on degranulation in mast cell RBL-2H3. Zhongguo Zhong Yao Za Zhi 36: 912-917, 2011 (In Chinese).

5. Yan S, Luo G, Wang Y and Cheng Y: Simultaneous determination of nine components in Qingkailing injection by HPLC/ELSD/DAD and its application to the quality control. J Pharm Biomed Anal 40: 889-895, 2006.

6. Leone R, Conforti A, Venegoni M, et al: Drug-induced anaphylaxis: case/non-case study based on an italian pharmacovigilance database. Drug Saf 28: 547-556, 2005.

7. Huang FH, Zhang XY, Zhang LY, et al: Mast cell degranulation induced by chlorogenic acid. Acta Pharmacol Sin 31: 849-854, 2010.

8. Berkes EA: Anaphylactic and anaphylactoid reactions to aspirin and other NSAIDs. Clin Rev Allergy Immunol 24: 137-148, 2003.

9. Fowler CJ, Sandberg M and Tiger G: Effects of water-soluble cigarette smoke extracts upon the release of beta-hexosaminidase from RBL-2H3 basophilic leukaemia cells in response to substance P, compound 48/80, concanavalin A and antigen stimulation. Inflamm Res 52: 461-469, 2003

10. Shefler I and Sagi-Eisenberg R: Gi-mediated activation of the Syk kinase by the receptor mimetic basic secretagogues of mast cells: role in mediating arachidonic acid/metabolites release. J Immunol 167: 475-481, 2001.
11. Ichikawa $A$, Koibuchi $Y$, Nakagawa $M$ and Tomita $K$ : $\mathrm{Ca}$-dependent and $\mathrm{Ca}$-independent histamine release from mast cells induced by active components of compound 48/80. Int J Tissue React 9: 325-333, 1987.

12. Nishida K, Yamasaki S, Ito Y, et al: Fc\{epsilon\}RI-mediated mast cell degranulation requires calcium-independent microtubule-dependent translocation of granules to the plasma membrane. J Cell Biol 170: 115-126, 2005.

13. Hinzey AH, Kline MA, Kotha SR, et al: Choice of cyclodextrin for cellular cholesterol depletion for vascular endothelial cell lipid raft studies: cell membrane alterations, cytoskeletal reorganization and cytotoxicity. Indian J Biochem Biophys 49: 329-341, 2012.

14. Doherty GJ and McMahon HT: Mediation, modulation, and consequences of membrane-cytoskeleton interactions. Annu Rev Biophys 37: 65-95, 2008.

15. Szebeni J, Muggia FM and Alving CR: Complement activation by Cremophor EL as a possible contributor to hypersensitivity to paclitaxel: an in vitro study. J Natl Cancer Inst 90: 300-306, 1998.

16. Vitale N, Chasserot-Golaz S, Bailly Y, Morinaga N, Frohman MA and Bader MF: Calcium-regulated exocytosis of dense-core vesicles requires the activation of ADP-ribosylation factor (ARF)6 by ARF nucleotide binding site opener at the plasma membrane. J Cell Biol 159: 79-89, 2002.

17. Allen JD, Jaffer ZM, Park SJ, et al: p21-activated kinase regulates mast cell degranulation via effects on calcium mobilization and cytoskeletal dynamics. Blood 113: 2695-2705, 2009.

18. Sagi-Eisenberg R and Pecht I: Membrane potential changes during IgE-mediated histamine release from rat basophilic leukemia cells. J Membr Biol 75: 97-104, 1983.

19. Hide I, Toriu N, Nuibe T, et al: Suppression of TNF-alpha secretion by azelastine in a rat mast (RBL-2H3) cell line: evidence for differential regulation of TNF-alpha release, transcription, and degranulation. J Immunol 159: 2932-2940, 1997.

20. Kawakami Y, Kitaura J, Hartman SE, Lowell CA, Siraganian RP and Kawakami T: Regulation of protein kinase CbetaI by two protein-tyrosine kinases, Btk and Syk. Proc Natl Acad Sci USA97: 7423-7428, 2000

21. Simon M, Vanes L, Geahlen RL and Tybulewicz VL: Distinct roles for the linker region tyrosines of Syk in FcepsilonRI signaling in primary mast cells. J Biol Chem 280: 4510-4517, 2005.

22. Axelrod D, Koppel DE, Schlessinger J, Elson E and Webb WW: Mobility measurement by analysis of fluorescence photobleaching recovery kinetics. Biophys J 16: 1055-1069, 1976.

23. Lin YL, Lu CK, Huang YJ and Chen HJ: Antioxidative caffeoylquinic acids and flavonoids from Hemerocallis fulva flowers. J Agric Food Chem 59: 8789-8795, 2011.

24. Wilson BS, Pfeiffer JR and Oliver JM: FcepsilonRI signaling observed from the inside of the mast cell membrane. Mol Immunol 38: 1259-1268, 2002.

25. Yamagishi $\mathrm{T}$ and Kawai $\mathrm{H}$ : Cytoskeleton organization during the cell cycle in two stramenopile microalgae, Ochromonas danica (Chrysophyceae) and Heterosigma akashiwo (Raphidophyceae), with special reference to F-actin organization and its role in cytokinesis. Protist 163: 686-700, 2012. 